\title{
Neuroprotective effect of nilotinib on pentylenetetrazol-induced epilepsy in adult rat hippocampus: involvement of oxidative stress, autophagy, inflammation, and apoptosis
}

\author{
Ghalia Mahfouz Attia ${ }^{1,2}$, Rasha Ahmed Elmansy ${ }^{3,4}$, Wael M. Elsaed ${ }^{1,5}$ \\ ${ }^{1}$ Department of Anatomy, Faculty of Medicine, Taibah University, Madinah, Kingdom of Saudi Arabia, ${ }^{2}$ Department of Histology and Cell \\ Biology, Faculty of Medicine, Mansoura University, Mansoura, Egypt, ${ }^{3}$ Department of Anatomy and Embryology, Faculty of Medicine, \\ Ain Shams University, Cairo, Egypt, ${ }^{4}$ Department of Anatomy, Faculty of Medicine, Unaizah College of Medicine, Al Qassim University, \\ Kingdom of Saudi Arabia, ${ }^{5}$ Anatomy and Embryology Department, Faculty of Medicine, Mansoura University, Mansoura, Egypt
}

\begin{abstract}
Introduction: Neuronal cell death and glial cell activation are the main pathological findings induced by seizures secondary to oxidative stress. Previous studies have explained neuronal cell death on the basis of cell necrosis and apoptosis. Recent studies have attributed the neuronal loss to autophagy. The proved antioxidant and antifibrotic effect of nilotinib favours its use in the management of epileptic seizures.

Aim of the study was to analyse the neuroprotective and antiepileptic effect of nilotinib and explain its mechanism of action.

Material and methods: Forty adult male rats were divided into four groups: control, pentylenetetrazol (PTZ) group (injected with PTZ $60 \mathrm{mg} / \mathrm{kg}$, s.c.), pregabalin (Pregb)-PTZ group (pretreated with pregabalin daily $30 \mathrm{mg} / \mathrm{kg}$; orally for 1 week) and nilotinib (NIL)-PTZ group (pretreated with nilotinib, 25 mg/kg daily for 1 week) prior to PTZ. Seizure latency was evaluated, the hippocampus tissue level of antioxidant enzymes was assessed. The histopathological changes in the hippocampus were studied using hematoxylin and eosin stain and immunohistochemical stain for brain-derived neurotrophic factor (BDNF), glial fibrillary acidic protein (GFAP), beclin-1, nuclear factor kappa-B (NF-kB) and Bcl-2-like protein 4 (BAX).

Results: Nilotinib induced an increase in the latency of seizures, enhanced the antioxidant levels of the $\gamma$-aminobutyric acid and nuclear factor (erythroid-derived 2)-like 2 activities together with the improvement of the hippocampal histology. A reduction was reported for BDNF, GFAP, beclin-1, NF-KB and BAX expression in nerve cells.

Conclusions: Nilotinib may have promising neuroprotective and antiepileptic effects against pentylenetetrazolinduced seizures through promoting the antioxidant, antifibrotic, anti-inflammatory, antiapoptotic pathways and inhibiting autophagy.
\end{abstract}

Key words: autophagy, apoptosis, hippocampus, epilepsy, nilotinib. 


\section{Introduction}

Epilepsy is a common chronic neurological disorder characterized by spontaneous recurrent seizures, affecting millions of people of all ages all over the world $[11,20]$. Epileptic seizures trigger neuronal death by a variety of mechanisms, of which, oxidative stress is the most common cause [2,32,51,77].

Previous studies reported the main pathological findings following epileptic seizures were neuronal cell death and glial cell activation [22,35]. The neurons of the hippocampus and the hilus of the dentate gyrus were the most affected brain areas [53]. Prevention of neuron loss and the glial cell activation has been a major aim of pharmaceutical research. Previous studies on epilepsy pathogenesis explained neuronal cell death which occurs in epileptic seizures and was based on cell necrosis and apoptosis [25]. Recent studies attributed the neuronal loss to a type of programmed cell death, called autophagy $[64,68,86]$.

Autophagy occurs in all eukaryotic cells as an important process for the maintenance of the intracellular homeostasis. Simply it is the process by which cells break down and reuse their organelles and macronutrients to maintain survival. Unfortunately, autophagy can paradoxically progress to cell death with prolonged stress $[6,46]$. Many studies proved that modifying autophagy can mitigate the outcome of an epileptic seizure [31]. However, the detailed mechanism of autophagy accompanying epilepsy is still unclear [27]. Epileptic seizures are always associated with the formation of reactive oxygen species (ROS) and oxidative stress in animal models of epilepsy [8]. Antiepileptic drugs having antioxidant properties were proven to have a neuroprotective effect on animals $[10,83]$.

Pregabalin (Pregb, Lyrica ${ }^{\oplus}$, Pfizer) is a routinely used antiepileptic with acceptable safety and tolerability [66] and was approved as a monotherapy for the management of refractory epilepsy [14]. Pregb acts by inhibiting release of glutamate from the presynaptic neurons by interaction with glial fibrillary acidic protein (GFAP) receptors [40]. Although Pregb is well tolerated, many side effects have been reported including the two most common, dizziness and sedation, along with peripheral oedema, dry mouth, and teratogenicity [76]. Resistance to anti-epileptics was reported in one-third of epileptic patients according to Pulman et al. [62].
Nilotinib (NIL) has been identified as a recent phenyl amino-pyrimidine derivative with marked selectivity against the Bcr-Abl tyrosine kinase [16]. Some studies proved that NIL has a favourable action in reducing oxidative stress and fibrosis in the rat model for renal disorders and liver injuries [38]. In Alzheimer's disease, it was found that NIL reduced amyloid accumulation and autophagic activities which was explained by tyrosine kinase inhibition and restoration of parkin-beclin-1 interaction [52].

The antioxidant and antifibrotic effects of NIL favour its use in the management of epileptic seizures. However, studies investigating this effect on experimental models of epilepsy are limited. The possible neuroprotective effect of NIL as a new antiepileptic drug on experimentally-induced acute epilepsy in rats was the aim of this study.

\section{Material and methods \\ Drugs}

Pregabalin (LYRICA CR ${ }^{\circledR}$-pregabalin tablet, 00711027, Pfizer Inc., Giza, Egypt) was suspended in $0.5 \%$ carboxymethyl cellulose (CMC).

Pentylenetetrazol (PTZ) (P6500, Millipore-Sigma, St Louis, MO, USA) was dissolved in $0.9 \%$ sterile normal saline.

Nilotinib was purchased from (TASIGNA ${ }^{\circledR} 200 \mathrm{mg}$ capsule, Novartis Pharmaceuticals UK Ltd Dublin, Ireland). It was ground to form a white to yellowish powder and dissolved in 0.5\% (CMC) and given to rats according to the determined dose.

\section{Animals}

Forty male adult rats (200 to 250 gm body weight) were obtained from the animal house of the Urology and Nephrology Centre, Manasoura University. Animals were kept under standard conditions of air and temperature throughout the experiment with diet and water obtained ad libitum. All steps of the experiment were in accordance to the regulations of the "Institutional Research Board" for Animal Experimentation, Faculty of Medicine, Mansoura University and the regulations of National Institute of Health Publications No. 80-23, Revised 1978. After one week of acclimatization the animals were divided into 4 groups (10 rats each) as follows:

The control group $(n=10)$ received $0.5 \%$ CMC as a vehicle one week before a subcutaneous (s.c.) 
injection with $10 \mathrm{ml} / \mathrm{kg}$ body weight (b.w.) sterile normal saline.

The PTZ group $(n=10)$ : the rats received $0.05 \%$ CMC one week before an s.c. injection with PTZ (60 mg/kg b.w.), according to de Oliveira et al. [23]. PTZ at a dose of $60 \mathrm{mg} / \mathrm{kg}$ b.w. was preferred as higher doses (70 mg and more) can cause more rapid death of rats.

The Pregb-PTZ group $(n=10)$ : the rats were pretreated with Pregb $(30 \mathrm{mg} / \mathrm{kg}$ b.w.) orally by a nasogastric tube according to Qureshi et al. [63] daily for one week before the injection with PTZ $60 \mathrm{mg} /$ $\mathrm{kg}$ b.w. PTZ was injected 1 hour after last treatment with Pregb.

The NIL-PTZ group $(n=10)$ : the rats were pretreated with NIL ( $25 \mathrm{mg} / \mathrm{kg}$ b.w.); orally by a nasogastric tube according to Karuppagounder et al. [43] daily for one week before the injection with PTZ. $60 \mathrm{mg} / \mathrm{kg}$ b.w. PTZ was injected 1 hour after the last treatment with NIL

After PTZ injection, all rats were placed in a glass observation box and PTZ-induced seizure and latency time were recorded over $45 \mathrm{~min}$. The seizure behaviour was classified according to Watanabe et al. [80] as follows: stage 0 , no response; stage 1 , ear and facial twitching; stage 2, myoclonic body jerks; stage 3 , forelimb clonus, rearing; stage 4 , clonic convulsions, turn onto the side; and stage 5 , generalized clonic convulsions, turn onto the back. The latencies to the onset of myoclonic jerks and generalized tonic-clonic seizures were recorded every minute for a total of 45 minutes [39].

\section{Hippocampus tissue collections}

One day after PTZ injection, the animals were humanely euthanized by sodium pentobarbital and then perfusion through the left ventricle was performed with $0.01 \mathrm{~mol} / / \mathrm{l}$ phosphate-buffered saline (PBS) followed by a fixative containing $4 \%$ paraformaldehyde, $0.05 \%$ glutaraldehyde and $0.2 \%$ picric acid in $0.1 \mathrm{~mol} / \mathrm{l}$ phosphate buffer ( $\mathrm{pH} 7.4)$. After decapitation of all rats, the brains were quickly removed and immersed into cold $0.05 \mathrm{M}$ PBS to prevent tissue drying and dissected. The hind brains were removed and the two hemispheres were separated by sagittal incisions. Meningeal and any non-cortical forebrain tissues were removed cautiously by forceps to avoid injury or cutting of the hippocampus. Then ten left hemispheres were postfixed in the same fixative of perfusion, then washed and embedded in paraffin to prepare paraffin blocks which were sectioned into 5 - $\mu \mathrm{m}$-thick sagittal sections. The sections were stained with hematoxylin and eosin stain [9] and immunohistochemical stain for localization of brain-derived neurotrophic factor (BDNF), GFAP, beclin 1, nuclear factor kappa-B (NF-KB) and $\mathrm{BCl}$-2-like protein 4 (BAX) antibodies immunoexpression in the hippocampus tissues using avidinbiotin-peroxidase complex techniques [36].

\section{Hippocampus homogenate preparation for biochemical assays}

The other ten right hemispheres per group were rapidly frozen at $-80^{\circ} \mathrm{C}$ before homogenization. Frozen hippocampi were then dissected away and homogenized in $0.05 \mathrm{M}$ phosphate buffer, $\mathrm{pH}$ 7.4, $(10 \% \mathrm{w} / \mathrm{v})$ on ice, in a homogenizer (Thomas PA, USA) at 10,000-15,000 rpm for 10 seconds. The tubes with homogenates were kept in ice water for $30 \mathrm{~min}$ and then centrifuged at $4^{\circ} \mathrm{C}(3000 \mathrm{~g}$ for $10 \mathrm{~min})$. The centrifuged supernatant of each sample was used to measure different biochemical parameters. Activities of hippocampus enzymatic antioxidants (superoxide dismutase (SOD), catalase (CAT), and glutathione peroxidase (GP-x)), non-enzymatic antioxidants (reduced glutathione (GSH) and lipid peroxidation by measuring malondialdehyde (MDA)) levels and nitrate/nitrite (NOx), an indicator of nitric oxide (NO) production were measured using commercially available Elisa kits (Bio-diagnostic Company, Giza, Egypt). Hippocampal contents of gamma-aminobutyric acid (GABA), and nuclear factor erythroid-derived 2-like 2 (Nrf2), were also evaluated using Elisa kits (MyBiosource, Inc., San Diego, CA, USA). The same procedure was used by Dong et al. [26].

\section{Immunohistochemical stain}

Paraffin sections were deparaffinized in xylene, rehydrated in descending ethyl alcohol gradient, rinsed in tap water and immersed in 3\% Hydrogen peroxide $\left(\mathrm{H}_{2} \mathrm{O}_{2}\right)$ in PBS for 10 min to block endogenous peroxidase. Sections were incubated overnight at $4^{\circ} \mathrm{C}$ with the respective primary antibodies: a rabbit anti-BDNF polyclonal IgG antibody (bs-4989R, concentration: $1 \mu \mathrm{g} / \mu \mathrm{l}$, Bioss, Woburn, Massachusetts, USA) diluted at $1: 200$, rabbit anti-GFAP polyclonal IgG antibody (PA5-16291, ThermoFisher Scientific, Rockford, IL, USA), diluted at $1: 100$, rabbit anti-beclin-1 polyclonal lgG antibody (bs-1353R, concentration: $1 \mu \mathrm{g} / \mu \mathrm{l}$, 
Bioss, Woburn, Massachusetts, USA) diluted at $1: 200$, rabbit anti-p-NF- $\kappa$ B p65 polyclonal IgG antibody (H-286 sc-7151, concentration: $200 \mu \mathrm{g} / \mathrm{ml}$, Bio-technology, Santa Cruz, CA, USA) diluted at $1: 100$ and mouse anti-BAX monoclonal IgG1 antibody (MA514003, clone; $6 \mathrm{~A} 7$, concentration; $0.2 \mathrm{mg} / \mathrm{ml}$, Thermo Fisher Scientific ${ }^{\mathrm{TM}}$, Waltham, MA, USA) diluted at $1: 50$.

Following incubation with the primary antibodies, the sections were then incubated with the appropriate secondary antibodies, Anti-Rabbit IgG $F(a b ') 2, F(a b ') 2$ fragment, highly cross absorbedBiotin antibody produced in goat (SAB3700844, Millipore, Sigma, St Louis, USA) for rabbit all detected primary antibodies and goat anti-Mouse IgG (HRP,31430, Thermo Fisher Scientific ${ }^{\text {TM}}$ ) for detection of BAX antibody. The sections were then incubated for $30 \mathrm{~min}$ at room temperature in horseradish peroxidase-avidin-biotin complex (Vectastain Elite, Vector, CA) then 3,3'-diaminobenzidine in $\mathrm{H}_{2} \mathrm{O}_{2}$ (DAB kit, Vector, $C A)$ to visualize the reaction as a brown, insoluble product detected in the cytoplasm in BDNF, GFAP and beclin-1 immunostained tissues and in the nuclei in NF- $\kappa B$ and $B A X$ immunostained sections. Sections were then counterstained with hematoxylin and mounted. Negative control sections were obtained following the same steps of staining, but without incubation with the primary antibodies.

\section{Morphometric study}

Pyramidal layer thickness $(\mu \mathrm{m})$ in hippocampus Cornu Ammonis (CA1) was measured microscopically at 400x magnification using a H\&E section from all rats $(n=40)$ from all four experimental groups. Ten measurements were taken from the widest and narrowest areas of CA1 pyramidal layer and the mean of these measurements was calculated for each $H \& E$ section. Three H\&E sections from each block were examined ( 3 sections $\times 10$ rats $=30$ ). Immunostaining of cells in CA1 immunopositive expressing for BDNF, GFAP, beclin $1, N F-\kappa B, B A X$ in CA1 were counted microscopically from IHC sections at $400 \times$ magnification. A section from each rat hippocampus block had three non-overlapping areas/section used for counting immunopositive cells for a total number of 30 measurements per experimental group ( 3 areas in a hippocampus section $\times 10$ rats $=30$ ). The sections were photographed using a colour video camera (digital camera CH-9435 DFC 290). Measurement results were analysed using Leica Qwin 500 Imaging Analysis System (Leica Microsystems
Image Solutions, Cambridge, UK) within a frame area equal to $293.4288 \mu^{2}$. The morphometric study was done at the Image Analysis Unit, Anatomy Department, Faculty of Medicine, Taibah University, Al Madinah Al Monawarrah, KSA.

\section{Statistical study}

All data were expressed as mean \pm SEM. Statistical analysis was performed using IBM SPSS software version 21.00 (Chicago, Illinois, USA) - one-way analysis of variance (ANOVA) (where data are normally distributed and variances of samples are equal) followed by post-hoc and least significant difference (LSD) for inter-group comparison. $P>0.05, P \leq 0.05$ and $P \leq 0.001$ were considered nonsignificant, significant and highly significant, respectively.

\section{Results}

\section{Effect of NIL versus Pregb pretreatment on the latencies (seizures threshold)/min to the onset of myoclonic and generalized tonic-clonic PTZ-induced convulsion}

Statistically, significant differences between groups were found (Fig. 1). No response was observed in control rats whereas PTZ-treated rats clearly

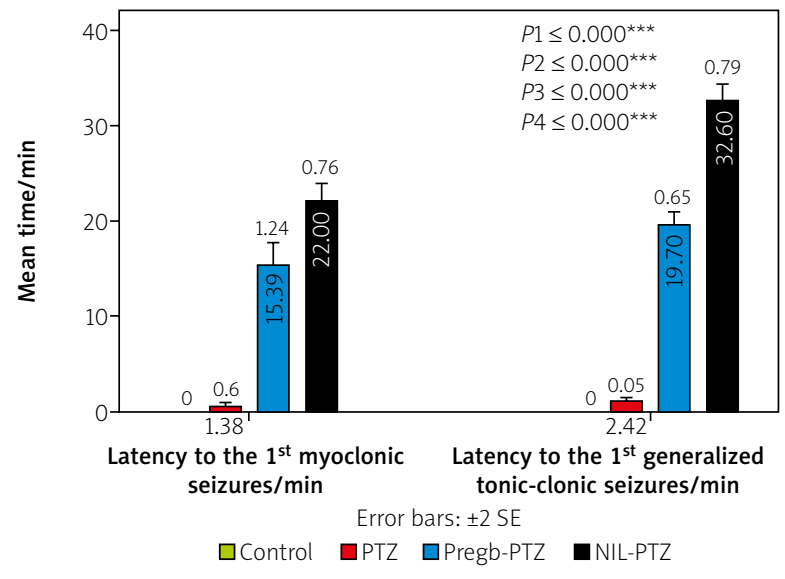

Fig. 1. Representative bars show the latencies (seizures threshold)/min to the onset of myoclonic and generalized tonic-clonic in control, PTZ, Pregb-PTZ and NIL-PTZ groups. Data are represented as mean $\pm S E M$.

SEM - standard error of mean, P - probability, *significant, ${ }^{* *}$ highly significant, ${ }^{* * *}$ very highly significant. Tests used: One way ANOVA followed by posthoc LSD test. $P 1$ - significance when control vs. PTZ groups. $P 2$ - Pregb-PTZ vs. PTZ groups. P3 - NIL-PTZ vs. PTZ groups. P4 - NIL-PTZ vs. Pregb-PTZ groups. 
exhibited severe convulsions where the onset of the first myoclonic seizures was after $1.38 \pm 0.6 \mathrm{~min}$ and the onset of the first generalized tonic-clonic seizure was after $2.42 \pm 0.05 \mathrm{~min}$. On the other hand, pretreatment with Pregb and NIL one week before PTZ injection showed a very highly significant increase in the seizure threshold (increased latency for the onset of clonic $-15.39 \pm 1.24, P 2 \leq 0.0001$ and $22 \pm 0.76, P 3 \leq 0.0001$ respectively, and for generalized tonic-clonic phases of convulsion $-19.70 \pm 0.65$, $P 2 \leq 0.0001$ and $32.60 \pm 0.79, P 3 \leq 0.0001$ respec tively) as compared to PTZ-treated animals. It was observed that NIL pretreatment was found to significantly ( $P 4 \leq 0.0001)$ delay the onset of seizures as compared to Pregb-treated rats, which indicates the protective effect of NIL against PTZ-induced seizures.

\section{Effect of Pregb and NIL pretreatment on oxidative stress markers and antioxidant status in hippocampus tissue homogenates in PTZ-induced convulsion}

A very highly significant elevation in hippocampal lipid peroxidation marker (MDA; $257 \pm 3.87$, $P \leq 0.0001$ ) with a marked decrease in levels of various hippocampal antioxidant markers such as SOD, GSH, GP-x and CAT (3.02 $\pm 0.32,72.60 \pm 1.93,32.30$ \pm 1.01 and $42.60 \pm 1.51, P \leq 0.0001$, respectively) were observed as the PTZ group was compared to the control group $(114.70 \pm 3.14,12.20 \pm 0.55,151.80 \pm 2.64$, $177.30 \pm 3.29$ and $545.70 \pm 2.95$, respectively) (Table I).

Compared to PTZ only treated rats, Pregb and NIL administration produced a reduction in MDA (194 \pm 2.72 ,
$136 \pm 2.14$, respectively, $P 2$ and $P 3 \leq 0.0001$ ) level that was still significantly higher than the control value. On the other hand, a highly significant improvement in hippocampal antioxidants levels; SOD, GSH, GP-x and CAT; were observed in the Pregb-PTZ group ( $9.40 \pm 0.40$, $114.10 \pm 3.33,137 \pm 2.35$ and $259.10 \pm 5.19$, respectively), $P 2 \leq 0.0001$ and the NIL-PTZ group $(10.60 \pm 0.48,140.60$ $\pm 4.00,152.70 \pm 4.25$ and $490.90 \pm 2.16$, respectively), P3 $\leq 0.0001$ as compared to the PTZ only treated group. However, NIL exhibited a higher elevation in hippocampal antioxidants levels of GSH, GP-x and CAT levels, $P 4 \leq 0.0001$ and a nonsignificant increase in SOD, P4 $=0.066$ as compared to the PTZ-Pregb group (Table I).

Regarding the level of NOx, it was observed that PTZ-induced convulsion in the rats was accompanied by a marked elevation in hippocampal NOx (188.70 $\pm 6.26, P 1 \leq 0.0001)$ as compared to control rats $(59.40 \pm 1.40)$. This elevated NOx level was significantly decreased by pretreatment with Pregb-PTZ $(99.50 \pm 2.20, P 2 \leq 0.0001)$ and NIL-PTZ (90.80 \pm 2.81 , $P 3 \leq 0.0001)$ as compared to the PTZ only treated group. A nonsignificant difference $(P 4=0.102)$ in NOx level was observed when the NIL-PTZ group compared to the Pregb-PTZ group (Table I).

\section{Effect of Pregb versus NIL pretreatment on GABA and NRf2 in hippocampus tissue homogenates in PTZ-induced convulsion}

A very highly significant reduction in the hippocampal tissue homogenates level of GABA and NRf2 ( $207 \pm 5.86$ and $13.30 \pm 0.87$, respectively, $P 1 \leq 0.0001$ ) were observed in the PTZ only treated group when

Table I. Mean concentration of malondialdehyde (MDA), superoxide dismutase (SOD), reduced glutathione (GSH), glutathione peroxidase (GP-x), catalase (CAT) and nitrate/nitrite (NOx) in the hippocampal tissue homogenates of control, PTZ, Pregb-PTZ and NIL-PTZ groups. $N=10$ /group

\begin{tabular}{|c|c|c|c|c|c|c|}
\hline Groups & $\begin{array}{c}\text { MDA } \\
\text { (nmol/gm } \\
\text { tissue) }\end{array}$ & $\begin{array}{c}\text { SOD } \\
\text { (U/gm } \\
\text { tissue) }\end{array}$ & $\begin{array}{c}\text { GSH } \\
\text { (uM/gm } \\
\text { tissue) }\end{array}$ & $\begin{array}{c}\text { GP-X } \\
\text { (uM/gm } \\
\text { tissue) }\end{array}$ & $\begin{array}{c}\text { CAT } \\
\text { (U/gm } \\
\text { tissue) }\end{array}$ & $\begin{array}{c}\text { NOx } \\
\text { (uM/gm tissue) }\end{array}$ \\
\hline Control & $114.70 \pm 3.14$ & $12.20 \pm 0.55$ & $151.80 \pm 2.64$ & $177.30 \pm 3.29$ & $545.70 \pm 2.95$ & $59.40 \pm 1.40$ \\
\hline $\begin{array}{l}\mathrm{PTZ} \\
\mathrm{P} 1\end{array}$ & $\begin{array}{l}257 \pm 3.87 \\
\leq 0.0001^{\star *}\end{array}$ & $\begin{array}{l}3.02 \pm 0.32 \\
\leq 0.0001^{* * *}\end{array}$ & $\begin{array}{l}72.60 \pm 1.93 \\
\leq 0.0001^{* * *}\end{array}$ & $\begin{array}{l}32.30 \pm 1.01 \\
\leq 0.0001^{* * *}\end{array}$ & $\begin{array}{l}42.60 \pm 1.51 \\
\leq 0.0001^{\star * *}\end{array}$ & $\begin{array}{l}188.70 \pm 6.26 \\
\leq 0.0001^{\star * *}\end{array}$ \\
\hline $\begin{array}{l}\text { Pregb-PTZ } \\
\text { P2 }\end{array}$ & $\begin{array}{l}194 \pm 2.72 \\
\leq 0.001^{\star \star \star}\end{array}$ & $\begin{array}{l}9.40 \pm 0.40 \\
\leq 0.0001^{\star * *}\end{array}$ & $\begin{array}{l}114.10 \pm 3.33 \\
\leq 0.0001^{* * *}\end{array}$ & $\begin{array}{c}137 \pm 2.35 \\
\leq 0.0001^{\star * *}\end{array}$ & $\begin{array}{l}259.10 \pm 5.19 \\
\leq 0.0001^{\star * *}\end{array}$ & $\begin{array}{l}99.50 \pm 2.20 \\
\leq 0.0001^{\star * *}\end{array}$ \\
\hline $\begin{array}{l}\text { NIL-PTZ } \\
\text { P3 } \\
\text { P4 }\end{array}$ & $\begin{aligned} & 136 \pm 2.14 \\
\leq & 0.0001^{\star * *} \\
\leq & 0.0001^{\star * *}\end{aligned}$ & $\begin{array}{c}10.60 \pm 0.48 \\
\leq 0.0001^{\star * *} \\
0.066\end{array}$ & $\begin{array}{l}140.60 \pm 4.00 \\
\leq 0.0001^{\star * *} \\
\leq 0.0001^{\star * *}\end{array}$ & $\begin{array}{c}152.70 \pm 4.25 \\
\leq 0.0001^{\star * *} \\
0.0001^{\star * *}\end{array}$ & $\begin{array}{l}490.90 \pm 2.16 \\
\leq 0.0001^{\star * *} \\
\leq 0.0001^{\star * *}\end{array}$ & $\begin{array}{c}90.80 \pm 2.81 \\
\leq 0.0001^{\star * *} \\
0.102\end{array}$ \\
\hline
\end{tabular}

Data are represented as mean \pm SEM. SEM - standard error of mean, $P$ - probability *significant, **highly significant, ${ }^{* * *}$ very highly significant. Tests used: One way ANOVA followed by post-hoc LSD test.

P1 - significance between Control and PTZ groups. P2 - significance between Pregb-PTZ and PTZ groups. P3 - significance between NIL-PTZ and PTZ groups. P4 - significance between NIL-PTZ and Pregb-PTZ groups. 
compared to the control group $(519 \pm 14.70$ and 33.20 \pm 1.70 , respectively). On the other hand, marked elevation in their level was observed in Pregb-PTZ $(393.70 \pm 11.76$ and $24.70 \pm 1.05, P 2 \leq 0.0001)$ and NILgroups ( $417.40 \pm 18.43$ and $26.70 \pm 1.24, P 3 \leq 0.0001)$ when compared to the PTZ group. There was no significant difference in the GABA and NRf2 levels in NIL-PTZ rats as compared to rats in the Pregb treated group ( $P 4=0.222$ and 0.268 , respectively) (Fig. 2).

\section{Effect of NIL and Pregb on PTZ- associated histological changes in Hippocampus cornu ammonis areas}

H\&E sections of the control group showed four different hippocampus cornu ammonis areas: CA1, CA2, CA3 and CA4, and the dentate gyrus (DG) (Fig. 3A). Cornu ammonis (CA1) showed pyramid shaped nerve cell bodies with round vesicular nuclei and prominent nucleoli whereas glial cells were small with small round dark nuclei (Fig. 3A1). In the PTZ group, most nerve cells were smaller, distorted in shape, contained deeply stained nuclei and reduced pyramidal nerve cell layer thickness (Fig. 3B and B1). In Pregb-PTZ (Fig. 3C and C1) and NIL-PTZ (Fig. 3D and D1) sections, the shape for the majority of nerve cells and thickness of the pyramidal nerve cell layer were similar to those seen in the control group.

Statistically, the mean thickness of the pyramidal nerve cell layer of CA1 showed a very highly significant decrease in the PTZ only treated group (22.33 $\pm 0.61, P 1 \leq 0.0001)$ as compared to the control group $(46.10 \pm 0.97)$. Pregb-PTZ and NIL-PTZ groups showed a marked increase in the thickness of the pyramidal layer $(32.63 \pm 1.03, P 2 \leq 0.0001$ and $38.27 \pm 0.98$, $P 3 \leq 0.0001$, respectively) as compared to the PTZ group. However, the NIL-PTZ group showed a much higher increase in the thickness of CA1 as compared to the Pregb-PTZ group ( $P 4 \leq 0.0001)$ (Fig. 4).

\section{Effect of NIL versus Pregb pretreatment on the number of cells expressing BDNF, GFAP, beclin-1, NF- $\kappa B$ and BAX markers in CA1 area with PTZ-induced convulsion}

Immunohistochemical staining on control rat sections showed some nerve cells in the CA1 pyramidal layer and exhibited BDNF expression in the cytoplasm (Fig. 5A). In the PTZ group, a strong BDNF expression was detected in most cells (Fig. 5B). Fewer BDNF positive cells were seen in Pregb-PTZ (Fig. 5C)

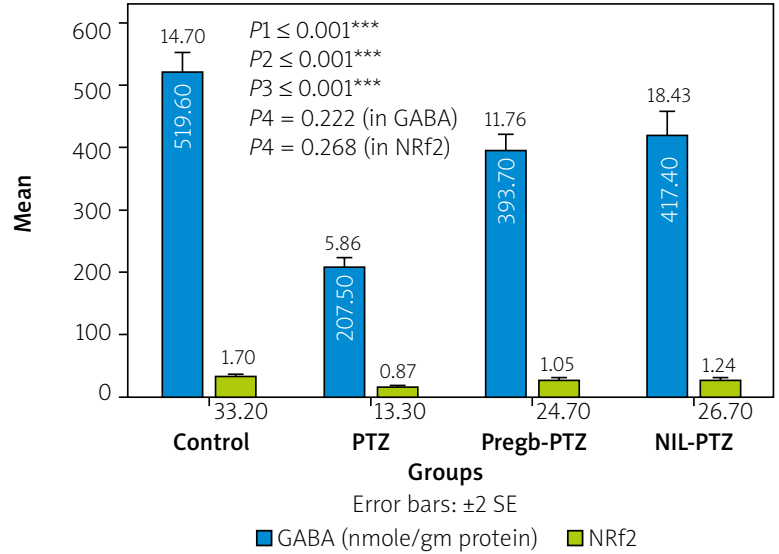

Fig. 2. Representative bars show the level of GABA and NRf2 in hippocampus tissue homogenates in control, PTZ, Pregb-PTZ and NIL-PTZ groups. Data are represented as mean \pm SEM. SEM - standard error of mean. P - probability, ${ }^{\star}$ significant, ${ }^{* *}$ highly significant, ${ }^{* * *}$ very highly significant. Tests used: One way ANOVA followed by posthoc LSD test. $P 1$ - significance when control vs. PTZ groups. $P 2$ - Pregb-PTZ vs. PTZ group. P3 - significance between NIL-PTZ and PTZ groups. P4 - significance between NIL-PTZ and Pregb-PTZ groups.

and NIL-PTZ (Fig. 5D) groups as compared to PTZ treated rats. There were many GFAP positive star-shaped glial cells in control rats (Fig. 5E) with GFAP expressed in the cell body cytoplasm and processes. The PTZ group had numerous GFAP positive cells (Fig. 5F) whereas, in Pregb-PTZ (Fig. 5G) and NIL-PTZ (Fig. 5H) groups, these positive cells were closer in number to the control group. The control group only had a few pyramidal nerve cells expressing beclin-1 in the cytoplasm (Fig. 5I). Nearly all nerve cells in the PTZ group (Fig. 5J) were beclin-1 positive while only some cells were positive in Pregb-PTZ (Fig. 5K) and NIL-PTZ (Fig. 5L) groups. For NF- $\kappa B$ expression, the control group (Fig. $5 \mathrm{M}$ ) showed that all nerve cells were NF- $\kappa B$ negative. However, in the PTZ group (Fig. $5 \mathrm{~N}$ ) the majority of nerve cells exhibited a strong

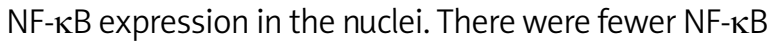
positive cells in Pregb-PTZ and NIL-PTZ groups (Fig. 50, 5P) as compared to the PTZ group (Fig. $5 \mathrm{~N}$ ). Nerve cells in the control group (Fig. 5Q) showed a negative BAX expression whereas most nerve cells in the PTZ group (Fig. 5R) expressed BAX in the nuclei with fewer BAX positive cells seen in Pregb-PTZ and NIL-PTZ groups (Fig. 5S and 5T).

In the PTZ only treated group, a very highly significant increase in the mean number of cells expressing 

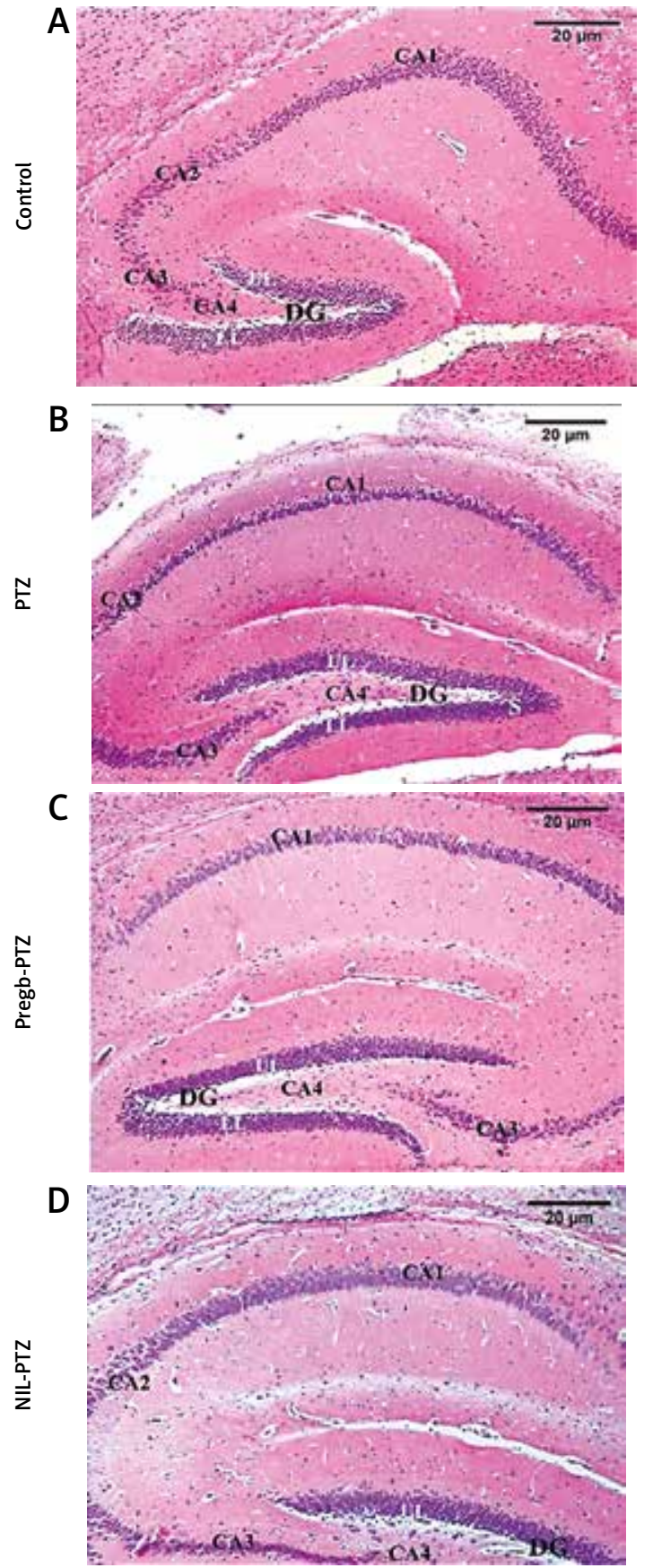

H\&E stain

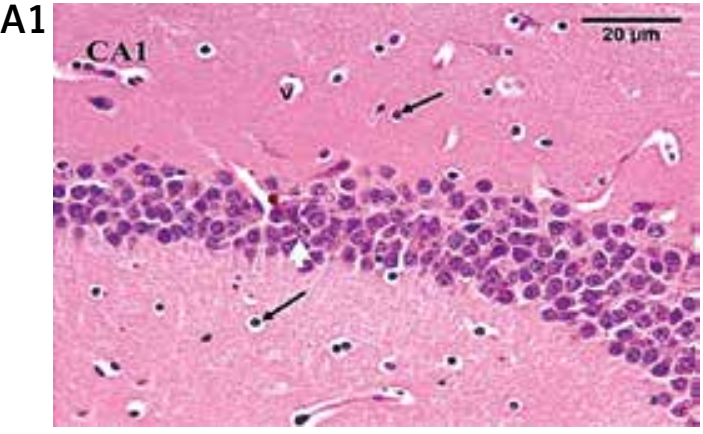

B1

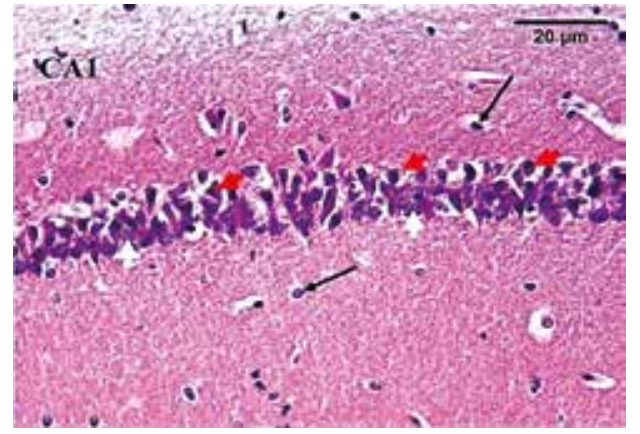

C1

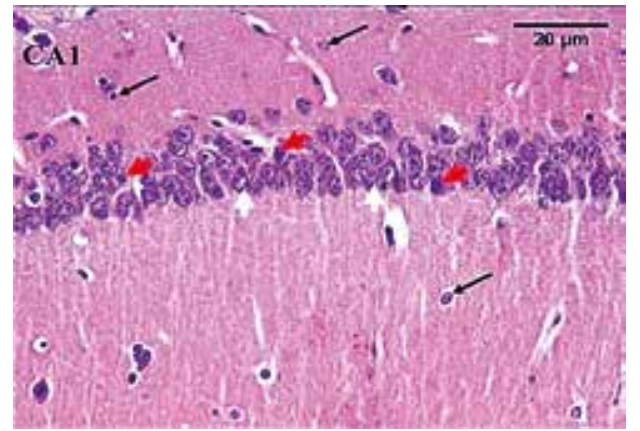

D1

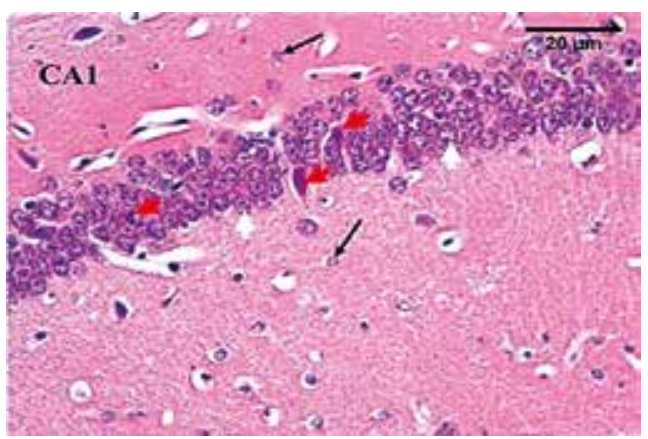

Fig. 3. A photomicrograph of rat hippocampus cornu ammonis areas $C A 1, C A 2, C A 3$, and $C A 4$ in the four experimental groups: (A, A1) Control; (B, B1) PTZ; (C, C1) Pregb-PTZ and (D, D1) NIL-PTZ show areas CA1, CA2, CA3. A, B, C, D points out dentate gyrus (DG), upper limb (UL), lower limb (LL). A, B, C show the stem (S) in curved dentate gyrus. A1) Control shows normal shaped pyramidal nerve cells with round vesicular nuclei, prominent nucleoli and many smaller glial cells with small round dark nuclei (long arrows). B1) PTZ shows reduced nerve cell layer thickness. Small cells have signs of degeneration, distorted shape, dark apoptotic nuclei and numerous glial cells. In (C1) Pregb-PTZ CA1 and (D1) NIL-PTZ CA1, most nerve cells have a normal shape (short arrows). The pyramidal nerve cell layer thickness appears preserved and mostly normal (white arrow heads - refer to normal pyramidal nerve cells, red arrow heads - refer to degenerated pyramidal nerve cells, and long arrows - refer to glial cells). H\&E stain; A, B, C and D ×100; A1, B1, C1 and D1 ×400, scale bar $=20 \mu \mathrm{m}$. 
BDNF GFAP, beclin-1, NF- $\kappa B$ and BAX were observed $(98.07 \pm 0.93,40.70 \pm 0.51,101.17 \pm 1.18,72.65 \pm 2.63$ and $59.30 \pm 0.33$, respectively, $P 1 \leq 0.0001)$ as compared to control rats $(15.07 \pm 0.33,19.96 \pm 0.33,4.13$ $\pm 0.37,00.00,1.17 \pm 0.20$, respectively). On the other hand, Pregb-PTZ and NIL-PTZ groups had a lower number of these cells. However NIL pretreatment provided a very highly significant decrease in positive immune stained cells as compared to Pregb $(P 4 \leq 0.0001)$ (Fig. 6).

\section{Discussion}

PTZ-induced convulsion is a widely accepted model for induction of seizures [85]. PTZ acts by antagonizing the action of GABA with accompanying oxidative stress caused by augmented production of superoxides and free radicals [72].

Pregb is a widely-used antiepileptic. It is a specific modulator of the alpha2 delta subunit of the presynaptic calcium channels with subsequent inhibition of neurotransmitter release [15]. It is used experimentally to compare newly proposed antiepileptics [63]. Nilotinib, a second-generation, selective tyrosine kinase inhibitor which was investigated in the present work to study its neuroprotective and hence its antiepileptic role in the PTZ epileptic rat model.

Although a considerable progress in understanding post-seizure cell death had been achieved, the exact mechanism underlying this process is still unclear [26]. The number and time of onset of seizures is an important marker of the drug activity. Our results showed a highly significant delay of onset of seizures in the NIL-PTZ group in comparison to Pregb-PTZ rats, indicate the protective effect of NIL against PTZ-induced seizures. The decreased latency of seizures was used as a marker of effective antiepileptic action [26,60].

Production of ROS and reduced antioxidant activities are the main causes of pathological changes in nervous tissue [3]. The whole brain is more liable to oxidative stress because of its high metabolic rate and low antioxidant capacity [78]. The hippocampal areas are more sensitive particularly to hypoxia [79]. This fact was explained by its low content of vitamin E which is an important antioxidant [21].

Oxidative damage in the brain induced by status epilepticus (SE) has been studied thoroughly where brain cells antioxidant defence was determined by measuring peroxidation (MDA) antioxidants (SOD, GSH, GP-X, and CAT). The present study showed a marked decrease in antioxidants in the PTZ group,

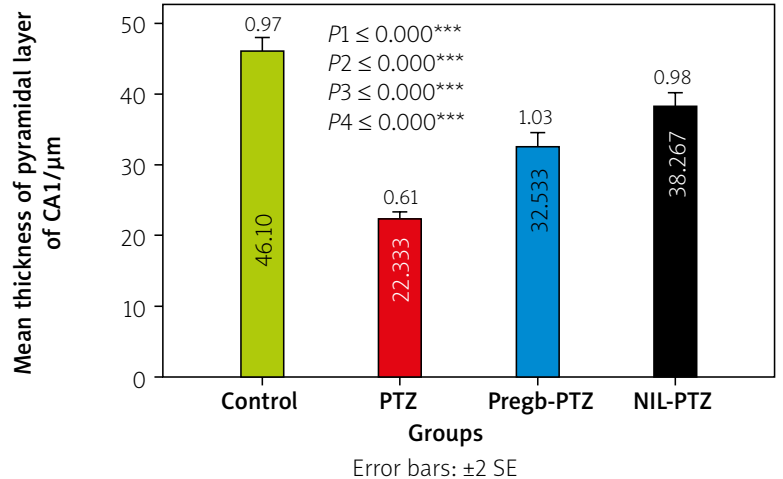

Fig. 4. Representative bars show mean thickness of the pyramidal nerve cell layer in CA1 of hippocampus of control, PTZ, Pregb-PTZ and NIL-PTZ groups. Data are represented as mean \pm SEM. SEM - standard error of mean. P - probability, *significant, ${ }^{* *}$ highly significant, ${ }^{* * *}$ very highly significant. Tests used: One way ANOVA followed by posthoc LSD test. $P 1$ - significance when control vs. PTZ groups. $P 2$ - Pregb-PTZ vs. PTZ group. $P 3$ - significance between NIL-PTZ and PTZ groups. $P 4-$ significance between NIL-PTZ and Pregb-PTZ groups.

marked improvement after Pregb and more improvement after NIL. Nilotinib was reported to have a similar potent antioxidant effect in renal, pulmonary and hepatic tissues $[28,57,69]$.

The present work demonstrated a marked elevation in hippocampal NOx in PTZ treated rats. Other studies show that NO has a principal role in nervous tissue physiologic and pathological conditions [30]. The NO level was linked to generation and propagation of the epileptiform activity [41].

On the other hand, pretreatment with Pregb and NIL in the hippocampus was found to reverse an elevated NO level to an almost normal control level indicating that these drugs have powerful suppressive oxidant and anti-oxidant defence effects. This action can be further explained on the molecular level by the drug action on NF- $\mathrm{KB}$ and NRf2 pathways [7,33]. It was found that Pregb attenuates the expression of $\mathrm{p}-\mathrm{NF}-\kappa \mathrm{B}$ and restore the activity and diminution of phosphorylation of NOS. The net result will be protection of the neuronal cell from the harms of peroxynitrite generation and nitrosylation of mitochondrial metabolic enzymes [24]. These findings propose that NIL anti-epileptiform occurred through NO-mediated mechanisms.

The demonstrated low level of GABA and NRf2 in the PTZ treated group and their marked eleva- 


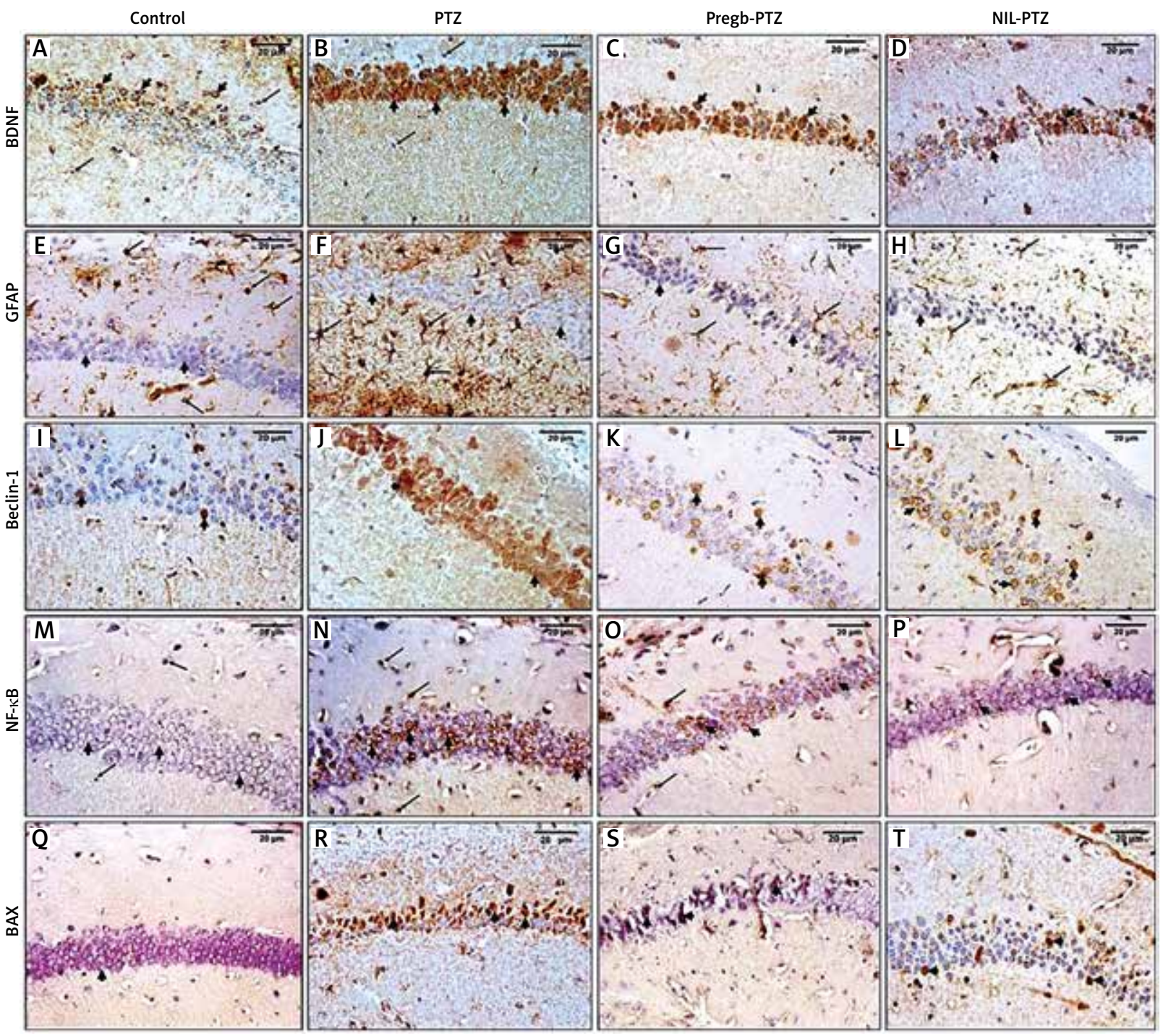

Fig. 5. A photomicrograph of $C A 1$ area of rat hippocampus; anti-BDNF immunostained sections ( $A, B, C$ and D): A) Control shows cytoplasmic BDNF expression in some nerve cells, B) PTZ group has strong BDNF expression in the majority of nerve cells, C, D) Pregb-PTZ and NIL-PTZ groups show numerous BDNF positive cells. Anti-GFAP immunostained sections (E, F, G and H): E) Control has GFAP positive shaped glial cells with cytoplasmic expression in cell and processes, F) PTZ shows a strong GFAP expression by numerous cells. However, in (G) Pregb-PTZ and (H) NIL-PTZ groups, GFAP expression is similar to number of cells in controls. Anti-beclin-1 immunostained sections (I, J, K and L): I) Control has fewer nerve cells with cytoplasmic beclin-1 expression whereas most nerve cells in (J) PTZ express beclin-1 whereas (K) Pregb-PTZ and (L) NIL-PTZ only a few cells express beclin-1. Anti-NF- $\kappa B$ immunostained sections ( $M, N, O$ and $P$ ): $M$ ) Control

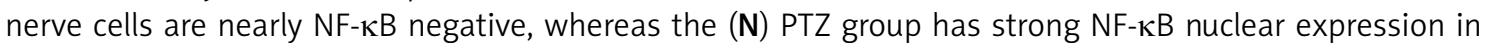

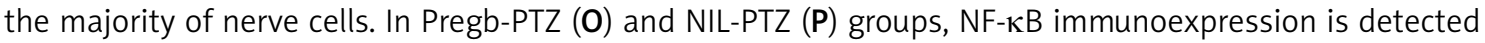
in fewer number of cells as compared to PTZ group. In anti-BAX immunostained sections $(\mathrm{Q}, \mathrm{R}, \mathrm{S}$ and $\mathrm{T})$ : Q) control group show a negative BAX expression, whereas most of nerve cells in PTZ group (R) show a positive BAX expression in nuclei. In Pregb-PTZ (S) and NIL-PTZ (T) groups, only few cells expressed BXA. Arrow heads refer to nerve cells and arrows refer to glial cells.

Anti-BDNF immunostained sections (A, B, C and D $\times 400$ ); anti-GFAP immunostained sections (E, F, G and $\mathrm{H}$ $\times 400$ ); anti-beclin-1 immunostained sections (I, J, K and L $\times 400$ ); anti-NF- $\kappa B$ immunostained sections ( $M, N$, $\mathrm{O}$ and $\mathrm{P} \times 400)$ and anti-BAX immunostained sections $(\mathrm{Q}, \mathrm{R}, \mathrm{S}$ and $\mathrm{T} \times 400)$, scale bar $=20 \mu \mathrm{m}$. 

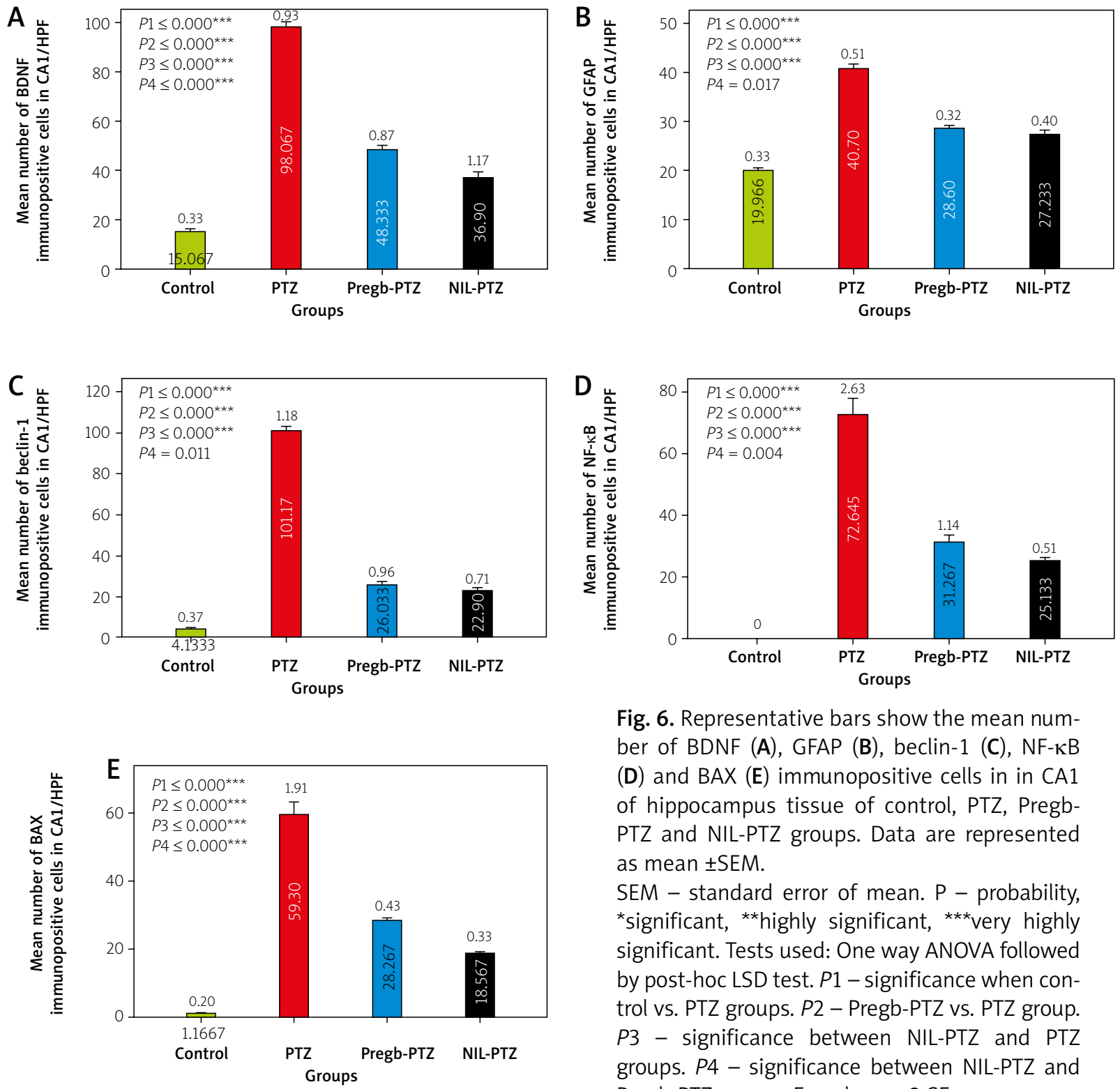

Fig. 6. Representative bars show the mean number of BDNF (A), GFAP (B), beclin-1 (C), NF-кB (D) and BAX (E) immunopositive cells in in CA1 of hippocampus tissue of control, PTZ, PregbPTZ and NIL-PTZ groups. Data are represented as mean $\pm S E M$.

SEM - standard error of mean. P - probability, *significant, ${ }^{* *}$ highly significant, ${ }^{* * *}$ very highly significant. Tests used: One way ANOVA followed by post-hoc LSD test. $P 1$ - significance when control vs. PTZ groups. $P 2-$ Pregb-PTZ vs. PTZ group. P3 - significance between NIL-PTZ and PTZ groups. P4 - significance between NIL-PTZ and Pregb-PTZ groups. Error bars: \pm 2 SE.

tion observed in Pregb and NIL treated groups in the present work provide the evidence of the neuroprotective role offered by NIL. SE-induced increased ROS have the ability to modify the action of NRf2 and $N F-\kappa B$ transcription factors [17]. Both factors can modify the antioxidant defence and the pro-inflammatory mediator expression [1]. NRf2 was reported as an activator of cell defence against harmful oxidative stress [18]. One of these defences is the suppression of NF- $\mathrm{KB}$ in a very complicated unclear mechanism [17]. The normal level of GABA elevates the excitatory threshold of the neurons by inducing

hypo polarization of the postsynaptic neurons [48]. PTZ induces seizures by antagonizing the action of GABA. This finding is always supported by the accompanying decrease in GABA concentration in brain tissue. The same finding was reported by previous researchers $[48,54]$.

Degenerated nerve cells with small-size and distorted shape in addition to the decrease in the mean thickness of the pyramidal nerve cell layer of CA1, which were evident in the PTZ group in the current work was supported by similar findings in the hippocampus during the acute phase of seizures $[67,82]$. Neuronal 
loss, gliosis, and vacuolation were also reported. Neuronal cell death following SE was mainly located in CA1 and CA3 layers of the hippocampus [26].

Cell death during SE is explained by increased production of glutamate which causes swelling of the cellular organelles and damages the intercellular membranes secondary to increased calcium overload [26]. On the other hand, the nilotinib treated group showed more protection to nerve cells in addition to preservation of the thickness of the pyramidal cell layer of CA1 when compared to PTZ treated one. This protective effect of nilotinib could be explained by its antioxidant role as reflected by our biochemical result mentioned above.

Study results showed that in PTZ-treated rats, nearly all nerve cells in the pyramidal layer exhibited strong BDNF expression whereas a fewer cells were positive in Pregb-PTZ and NIL-PTZ groups. BDNF is one of the nerve growth factors that support the survival and the normal functions of nerve cells. The highest concentration of BDNF is known to be in the hippocampus [44]. Its expression was found to increase in various models of epilepsy [12] due to active neo-synthesis resulting from shift of BDNF from inside the neuron to the surrounding neuropil 2-3 hours after seizure [81]. BDNF enhances the presynaptic neurotransmitter release and the postsynaptic receptor response. This action ends in exaggerated impulse transmission and seizures caused by increasing the neuronal excitability and has a pro-epileptic role by potentiating excitatory synapses [75].

Moreover, BDNF inhibits GABA-dependent neurotransmission by downregulation of protein kinases. The enhanced expression of BDNF following PTZ administration was also reported [34]. Therefore the anti-epileptic effect of NIL could be supported by its decrease to BDNF expression by the nerve cells of the hippocampus as proved in the present work.

GFAP is a marker of astrocyte activation following injury or stress of the brain [87]. GFAP enhances the inflammatory response in the nervous tissue through inhibiting neuronal death [49]. Being a part of the filament protein system, it is involved in regulation of the cell size and migration [59]. Neuronal injury is followed by microglial cell activation [24]. PTZ was reported to induce astrogliosis $[4,50,65]$.

Astrogliosis is a condition of hypertrophy of the cell bodies and processes of the astrocytes. It is a pathologic finding of epileptic foci is associated with an increased expression of glial fibrillary protein produced in response to astrocytes reaction to various insults [56]. This was in agreement with the present work which detected reactive astrogliosis in PTZ induced seizures and in turn increased GFAP immunoreactivity. On the other hand, the near normal expression observed in NIL-PTZ groups indicates less stress and tissue damage which in turn raises the probability of the anti-epileptic role of NIL.

A significant increase in beclin-1 expression was detected in the PTZ group indicating an autophagy pathway activation. On the other hand in Pregb-PTZ and NIL-PTZ groups, a fewer number of cells were beclin-1 immunopositive with decreased expression indicating the suppressor effect of Pregb and NIL on autophagy. One of the involved autophagic promoting proteins is beclin-1. Autophagy is a dynamic critical cellular activity that aims to turn over the cytoplasmic components [55]. The process involves the production of auto-phagosome; an intermediate cytoplasmic vacuolar structure that delivers the substrates to the lysosomes [5].

Oxidative stress, a major contributing factor in neurotoxicity, ROS production was shown to induce autophagy in many diseases rather than the nervous tissue but the neurons are particularly sensitive to this process [26]. This is explained by the fact that full differentiated nerve cells have a very specialized structure and will not be able to dilute the damaged organelles and proteins through a next cell division [70]. ROS regulates autophagy by promoting either cell survival or cell death, depending upon the severity of stress occurring with a particular disease $[19,61]$. Studies showed that in the brain tissue, the cellular autophagic activity may be rapidly increased in response to oxidative stress that occurs during seizures [58,74].

Similarly, autophagy was found to increase in experimental models of PTZ-induced seizures [89]. Pregb and NIL pretreated rats in the present work showed weak beclin-1 expression indicating suppression of autophagy, which agreed with another study that reported inhibited autophagy had a protective response against acute neuronal injury [88].

In the PTZ group, the majority of nerve cells exhib-

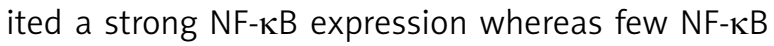
positive cells were observed in Pregb-PTZ and NIL-PTZ groups with much better results in NIL. NF-KB is an essential molecule for gene transcription and stability of mRNA [13]. Its expression increases secondary 
to oxidative stress. Activation of NF- $\kappa B$ by oxidative stress is under control of NRf2 transcription activation [71]. Previous studies proved the ability of NRf2

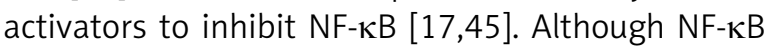
expression in epileptic patients increased, a possibility to increase its expression through activating the NRf2 pathway had been tried in scarce scientific studies [73]. In our results, the elevated NRf2 level in hippocampus after NIL treatment could explain the diminished NF- $\mathrm{KB}$ expression. These consequences indicate decreased oxidative stress and hence the antiepileptic effect of NIL.

The significant increase in the number of apoptotic nerve cells marked by BAX expression and the fewer cells in Pregb-PTZ and NIL-PTZ groups was supported by another study where the proapoptotic protein BAX had an important role in neuron death induced by seizures [29]. Although apoptosis and autophagy are different cellular activities, they share some regulatory steps [47]. The autophagic activity in the brain tissue can proceed to apoptosis including acute oxidative stress by an unclear mechanism [26]. The autophagic induced cell death is regulated by beclin-1 [42]. Its upregulation induced by ROS induces cell death [37]. Diminished expression of BAX in Pregb-PTZ and NIL-PTZ groups indicated a decreased cell death oxidative stress. Autophagy is most likely considered as a beneficial cellular response to stress which is the reverse of apoptosis [84].

The current results showed that NIL and/or Pregb treatments induced improvement in the autophagic process evidenced by increased beclin-1 expression and apoptosis as indicated by reduced BAX expression. Although a more or less protective effect of NIL and Pregb was the final result, NIL had better results regarding the increase in the seizure latency and enhance GABA and NRf2 activities, improved pyramidal cell layer histological picture, in addition to decreasing BDNF, beclin-1, NF- $\mathrm{B}$ B and BAX expression by nerve cells and GFAP by glial cells in CA1 when compared to Pregb treated rats.

\section{Conclusions}

Nilotinib may have a promising role in the management of epilepsy as it provides marked neuroprotective effects through promoting antioxidant, antifibrotic, anti-inflammatory and antiapoptotic pathways and inhibiting autophagy. Further experimental and clinical studies to confirm this beneficial effect are recommended.

\section{Disclosure}

The authors report no conflict of interest.

\section{References}

1. Abdelsalam RM, Safar MM. Neuroprotective effects of vildagliptin in rat rotenone Parkinson's disease model: role of RAGE-NFkappaB and Nrf2-antioxidant signaling pathways. J Neurochem 2015; 133: 700-707.

2. Agarwal NB, Jain S, Agarwal NK, Mediratta PK, Sharma KK. Modulation of pentylenetetrazole-induced kindling and oxidative stress by curcumin in mice. Phytomedicine 2011; 18: 756-759.

3. Aguiar CC, Almeida AB, Araujo PV, Vasconcelos GS, Chaves EM, do Vale OC, Macedo DS, Leal LK, de Barros Viana GS, Vasconcelos SM. Effects of agomelatine on oxidative stress in the brain of mice after chemically induced seizures. Cell Mol Neurobiol 2013; 33: 825-835.

4. Ahmed MM, Arif M, Chikuma T, Kato T. Pentylenetetrazol-induced seizures affect the levels of prolyl oligopeptidase, thimet oligopeptidase and glial proteins in rat brain regions, and attenuation by MK-801 pretreatment. Neurochem Int 2005; 47: 248-259.

5. Antonioli M, Di RM, Piacentini M, Fimia GM. Emerging mechanisms in initiating and terminating autophagy. Trends Biochem Sci 2017; 42: 28-41.

6. Ariosa AR, Klionsky DJ. Long-distance autophagy. Autophagy 2015; 11: 193-194.

7. Asci S, Demirci S, Asci H, Doguc DK, Onaran I. Neuroprotective effects of pregabalin on cerebral ischemia and reperfusion. Balkan Med J 2016; 33: 221-227.

8. Ayyildiz M, Coskun S, Yildirim M, Agar E. The effects of ascorbic acid on penicillin-induced epileptiform activity in rats. Epilepsia 2007; 48: 1388-1395.

9. Banchroft J. SATD. Theory and practice of histological techniques. Churchill Livingstone, London 1996.

10. Bashkatova V, Narkevich V, Vitskova G, Vanin A. The influence of anticonvulsant and antioxidant drugs on nitric oxide level and lipid peroxidation in the rat brain during penthylenetetrazole-induced epileptiform model seizures. Prog Neuropsychopharmacol Biol Psychiatry 2003; 27: 487-492.

11. Bell GS, Neligan A, Sander JW. Commentary: epilepsia's survey on the prevalence of epilepsy. Epilepsia 2015; 56: 166.

12. Biagini G, Avoli M, Marcinkiewicz J, Marcinkiewicz M. Brainderived neurotrophic factor superinduction parallels antiepileptic - neuroprotective treatment in the pilocarpine epilepsy model. J Neurochem 2001; 76: 1814-1822.

13. Bianchi R, Giambanco I, Donato R. S100B/RAGE-dependent activation of microglia via NF-kappaB and AP-1 Co-regulation of COX-2 expression by S100B, IL-1beta and TNF-alpha. Neurobiol Aging 2010; 31: 665-677.

14. Blommel ML, Blommel AL. Pregabalin: an antiepileptic agent useful for neuropathic pain. Am J Health Syst Pharm 2007; 64: 1475-1482. 
15. Bockbrader HN, Wesche D, Miller R, Chapel S, Janiczek N, Burg er P. A comparison of the pharmacokinetics and pharmacodynamics of pregabalin and gabapentin. Clin Pharmacokinet 2010; 49: 661-669.

16. Breccia M, Alimena G. Nilotinib: a second-generation tyrosine kinase inhibitor for chronic myeloid leukemia. Leuk Res 2010; 34: 129-134.

17. Buelna-Chontal M, Zazueta C. Redox activation of Nrf2 \& NF-kappaB: a double end sword? Cell Signal 2013; 25: 2548 2557.

18. Carmona-Aparicio L, Perez-Cruz C, Zavala-Tecuapetla C, Granados-Rojas L, Rivera-Espinosa L, Montesinos-Correa H, Hernandez-Damian J, Pedraza-Chaverri J, Sampieri A, III, Coballase-Urrutia E, Cardenas-Rodriguez N. Overview of Nrf2 as therapeutic target in epilepsy. Int J Mol Sci 2015; 16: 18348-18367.

19. Ceru S, Layfield R, Zavasnik-Bergant T, Repnik U, Kopitar-Jerala N, Turk V, Zerovnik E. Intracellular aggregation of human stefin B: confocal and electron microscopy study. Biol Cell 2010; 102: 319-334.

20. de Boer HM, Mula M, Sander JW. The global burden and stigma of epilepsy. Epilepsy Behav 2008; 12: 540-546.

21. de Freitas RL, Santos IM, de Souza GF, Tome AR, Saldanha GB, de Freitas RM. Oxidative stress in rat hippocampus caused by pilocarpine-induced seizures is reversed by buspirone. Brain Res Bull 2010; 81: 505-509.

22. De Lanerolle NC, Kim JH, Williamson A, Spencer SS, Zaveri HP Eid T, Spencer DD. A retrospective analysis of hippocampal pathology in human temporal lobe epilepsy: evidence for dis tinctive patient subcategories. Epilepsia 2003; 44: 677-687.

23. de Oliveira CC, de Oliveira CV, Grigoletto J, Ribeiro LR, Funck VR, Grauncke AC, de Souza TL, Souto NS, Furian AF, Menezes IR, Oliveira MS. Anticonvulsant activity of beta-caryophyllene against pentylenetetrazol-induced seizures. Epilepsy Behav 2016; 56: 26-31.

24. Demchenko IT, Atochin DN, Boso AE, Astern J, Huang PL, Piantadosi CA. Oxygen seizure latency and peroxynitrite formation in mice lacking neuronal or endothelial nitric oxide synthases. Neurosci Lett 2003; 344: 53-56.

25. Dingledine R, Varvel NH, Dudek FE. When and how do seizures kill neurons, and is cell death relevant to epileptogenesis? Adv Exp Med Biol 2014; 813: 109-122.

26. Dong Y, Wang S, Zhang T, Zhao X, Liu X, Cao L, Chi Z. Ascorbic acid ameliorates seizures and brain damage in rats through inhibiting autophagy. Brain Res 2013; 1535: 115-123.

27. Duran J, Gruart A, Garcia-Rocha M, Delgado-Garcia JM, Guinovart JJ. Glycogen accumulation underlies neurodegeneration and autophagy impairment in Lafora disease. Hum Mol Genet 2014; 23: 3147-3156.

28. El-Agamy DS. Nilotinib ameliorates lipopolysaccharide-induced acute lung injury in rats. Toxicol Appl Pharmacol 2011; 253: $153-$ 160.

29. Engel T, Henshall DC. Apoptosis, BCl-2 family proteins and caspases: the $A B C$ s of seizure-damage and epileptogenesis? Int J Physiol Pathophysiol Pharmacol 2009; 1: 97-115.

30. Forstermann U, Sessa WC. Nitric oxide synthases: regulation and function. Eur Heart J 2012; 33: 829-837.
31. Giorgi FS, Biagioni F, Lenzi P, Frati A, Fornai F. The role of autophagy in epileptogenesis and in epilepsy-induced neuronal alterations. J Neural Transm (Vienna.) 2015; 122: 849-862.

32. Grosso S, Longini M, Rodriguez A, Proietti F, Piccini B, Balestri P, Buonocore G. Oxidative stress in children affected by epileptic encephalopathies. J Neurol Sci 2011; 300: 103-106.

33. Ha KY, Kim YH, Rhyu KW, Kwon SE. Pregabalin as a neuroprotector after spinal cord injury in rats. Eur Spine J 2008; 17: 864-872.

34. Hao F, Jia LH, Li XW, Zhang YR, Liu XW. Garcinol Upregulates GABAA and GAD65 expression, modulates BDNF-TrkB pathway to reduce seizures in pentylenetetrazole (PTZ)-induced epilepsy. Med Sci Monit 2016; 22: 4415-4425.

35. Hirose G. An overview of epilepsy: its history, classification, pathophysiology and management. Brain Nerve 2013; 65: 509520.

36. Hsu SM, Raine L, Fanger $H$. Use of avidin-biotin-peroxidase complex $(A B C)$ in immunoperoxidase techniques: a comparison between $A B C$ and unlabeled antibody (PAP) procedures. J Histochem Cytochem 1981; 29: 577-580.

37. Hwang J, Lee S, Lee JT, Kwon TK, Kim DR, Kim H, Park HC, Suk K. Gangliosides induce autophagic cell death in astrocytes. Br J Pharmacol 2010; 159: 586-603.

38. Iyoda M, Shibata T, Hirai Y, Kuno Y, Akizawa T. Nilotinib attenuates renal injury and prolongs survival in chronic kidney disease. J Am Soc Nephrol 2011; 22: 1486-1496.

39. Jain S, Agarwal NB, Mediratta PK, Sharma KK. Evaluation of anticonvulsant and nootropic effect of ondansetron in mice. Hum Exp Toxicol 2012; 31: 905-912.

40. Joshi I, Taylor CP. Pregabalin action at a model synapse: binding to presynaptic calcium channel alpha2-delta subunit reduces neurotransmission in mice. Eur J Pharmacol 2006; 553: 82-88.

41. Kaneko K, Itoh K, Berliner LJ, Miyasaka K, Fujii H. Consequences of nitric oxide generation in epileptic-seizure rodent models as studied by in vivo EPR. Magn Reson Med 2002; 48: 1051-1056.

42. Kang R, Zeh HJ, Lotze MT, Tang D. The Beclin 1 network regulates autophagy and apoptosis. Cell Death Differ 2011; 18: 571-580.

43. Karuppagounder SS, Brahmachari S, Lee Y, Dawson VL, Dawson TM, Ko HS. The c-Abl inhibitor, nilotinib, protects dopaminergic neurons in a preclinical animal model of Parkinson's disease. Sci Rep 2014; 4: 4874.

44. Katoh-Semba R, Takeuchi IK, Semba R, Kato K. Distribution of brain-derived neurotrophic factor in rats and its changes with development in the brain. J Neurochem 1997; 69: 34-42.

45. Kim J, Cha YN, Surh YJ. A protective role of nuclear factor-erythroid 2-related factor-2 (Nrf2) in inflammatory disorders. Mutat Res 2010; 690: 12-23.

46. Klionsky DJ. Autophagy: research topic, painting, poem, dance...: The combination of art and information can enhance the enjoyment and effectiveness of learning. EMBO Rep 2015; 16: 547-552.

47. KnaufC, Cani PD, Kim DH, Iglesias MA, Chabo C, Waget A, Colom A, Rastrelli S, Delzenne NM, Drucker DJ, Seeley RJ, Burcelin R. Role of central nervous system glucagon-like Peptide-1 receptors in enteric glucose sensing. Diabetes 2008; 57: 2603-2612.

48. Koshal P, Kumar P. Neurochemical modulation involved in the beneficial effect of liraglutide, GLP-1 agonist on PTZ kindling 
epilepsy-induced comorbidities in mice. Mol Cell Biochem 2016; 415: 77-87.

49. Lefrancois T, Fages C, Peschanski M, Tardy M. Neuritic outgrowth associated with astroglial phenotypic changes induced by antisense glial fibrillary acidic protein (GFAP) mRNA in injured neuron-astrocyte cocultures. J Neurosci 1997; 17: 41214128.

50. Li B, Wang L, Sun Z, Zhou Y, Shao D, Zhao J, Song Y, Lv J, Dong X, Liu C, Wang P, Zhang X, Cui R. The anticonvulsant effects of SR 57227 on pentylenetetrazole-induced seizure in mice. PLoS One 2014; 9: e93158.

51. Li G, Bauer S, Nowak M, Norwood B, Tackenberg B, Rosenow F, Knake S, Oertel WH, Hamer HM. Cytokines and epilepsy. Seizure 2011; 20: 249-256.

52. Lonskaya I, Hebron ML, Selby ST, Turner RS, Moussa CE. Nilotinib and bosutinib modulate pre-plaque alterations of blood immune markers and neuro-inflammation in Alzheimer's disease models. Neuroscience 2015; 304: 316-327.

53. Lopes MW, Lopes SC, Costa AP, Goncalves FM, Rieger DK, Peres TV, Eyng H, Prediger RD, Diaz AP, Nunes JC, Walz R, Leal RB. Regionspecific alterations of AMPA receptor phosphorylation and signaling pathways in the pilocarpine model of epilepsy. Neurochem Int 2015; 87: 22-33.

54. Loscher W. Relationship between drug-induced changes in seizure thresholds and the GABA content of brain and brain nerve endings. Naunyn Schmiedebergs Arch Pharmacol 1981; 317: 131-134

55. McMahon J, Huang X, Yang J, Komatsu M, Yue Z, Qian J, Zhu X, Huang Y. Impaired autophagy in neurons after disinhibition of mammalian target of rapamycin and its contribution to epileptogenesis. J Neurosci 2012; 32: 15704-15714.

56. Morizawa YM, Hirayama Y, Ohno N, Shibata S, Shigetomi E, Sui Y, Nabekura J, Sato K, Okajima F, Takebayashi H, Okano H, Koizumi S. Reactive astrocytes function as phagocytes after brain ischemia via ABCA1-mediated pathway. Nat Commun 2017; 8: 28.

57. Nader MA, Attia GM. Beneficial effects of nilotinib, tyrosine kinase inhibitor on cyclosporine-A induced renal damage in rats. Int Immunopharmacol 2016; 33: 1-7.

58. Naziroglu M, Kutluhan S, Yilmaz M. Selenium and topiramate modulates brain microsomal oxidative stress values, Ca2+ATPase activity, and EEG records in pentylentetrazol-induced seizures in rats. J Membr Biol 2008; 225: 39-49.

59. Pekny M, Lane EB. Intermediate filaments and stress. Exp Cell Res 2007; 313: 2244-2254.

60. Pitkanen A. Treatment with antiepileptic drugs: possible neuroprotective effects. Neurology 1996; 47: S12-S16.

61. Pivtoraiko VN, Stone SL, Roth KA, Shacka JJ. Oxidative stress and autophagy in the regulation of lysosome-dependent neuron death. Antioxid Redox Signal 2009; 11: 481-496.

62. Pulman J, Hemming K, Marson AG. Pregabalin add-on for drug-resistant partial epilepsy. Cochrane Database Syst Rev 2014; CD005612.

63. Qureshi IH, Riaz A, Khan RA, Siddiqui AA. Synergistic anticonvulsant effects of pregabalin and amlodipine on acute seizure model of epilepsy in mice. Metab Brain Dis 2017; 32: 1051-1060.
64. Ryther RC, Wong M. Mammalian target of rapamycin (mTOR) inhibition: potential for antiseizure, antiepileptogenic, and epileptostatic therapy. Curr Neurol Neurosci Rep 2012; 12: 410-418.

65. Santana-Coelho D, Souza-Monteiro JR, Paraense RSO, Busanello GL, Arrifano GPF, Mendonca JR, Silveira-Junior MEP, Royes LFF, Crespo-Lopez ME. Antidepressant drugs in convulsive seizures: Pre-clinical evaluation of duloxetine in mice. Neurochem Int 2016; 99: 62-71.

66. Schulze-Bonhage A. Epilepsies and their medical treatment. Med Monatsschr Pharm 2010; 33: 207-214.

67. Scorza FA, Arida RM, Naffah-Mazzacoratti MG, Scerni DA, Calderazzo L, Cavalheiro EA. The pilocarpine model of epilepsy: what have we learned? An Acad Bras Cienc 2009; 81: 345-365.

68. Shacka JJ, Lu J, Xie ZL, Uchiyama Y, Roth KA, Zhang J. Kainic acid induces early and transient autophagic stress in mouse hippocampus. Neurosci Lett 2007; 414: 57-60.

69. Shaker ME, Zalata KR, Mehal WZ, Shiha GE, Ibrahim TM. Comparison of imatinib, nilotinib and silymarin in the treatment of carbon tetrachloride-induced hepatic oxidative stress, injury and fibrosis. Toxicol Appl Pharmacol 2011; 252: 165-175.

70. Son JH, Shim JH, Kim KH, Ha JY, Han JY. Neuronal autophagy and neurodegenerative diseases. Exp Mol Med 2012; 44: 89-98.

71. Song Y, Zhang F, Ying C, Kumar KA, Zhou X. Inhibition of NF-kap$\mathrm{paB}$ activity by aminoguanidine alleviates neuroinflammation induced by hyperglycemia. Metab Brain Dis 2017; 32: 1627-1637.

72. Taiwe GS, Moto FC, Ayissi ER, Ngoupaye GT, Njapdounke JS, Nkantchoua GC, Kouemou N, Omam JP, Kandeda AK, Pale S, Pahaye D, Ngo BE. Effects of a lyophilized aqueous extract of Feretia apodanthera Del. (Rubiaceae) on pentylenetetrazole-induced kindling, oxidative stress, and cognitive impairment in mice. Epilepsy Behav 2015; 43: 100-108.

73. Teocchi MA, Ferreira AE, da Luz de Oliveira EP, Tedeschi H, D'Souza-Li L. Hippocampal gene expression dysregulation of Klotho, nuclear factor kappa B and tumor necrosis factor in temporal lobe epilepsy patients. J Neuroinflammation 2013; 10: 53.

74. Tizon B, Sahoo S, Yu H, Gauthier S, Kumar AR, Mohan P, Figliola M, Pawlik M, Grubb A, Uchiyama Y, Bandyopadhyay U, Cuervo AM, Nixon RA, Levy E. Induction of autophagy by cystatin C: a mechanism that protects murine primary cortical neurons and neuronal cell lines. PLoS One 2010; 5: e9819.

75. Tongiorgi E, Armellin M, Giulianini PG, Bregola G, Zucchini S, Paradiso B, Steward O, Cattaneo A, Simonato M. Brain-derived neurotrophic factor mRNA and protein are targeted to discrete dendritic laminas by events that trigger epileptogenesis. J Neurosci 2004; 24: 6842-6852.

76. Toth C. Pregabalin: latest safety evidence and clinical implications for the management of neuropathic pain. Ther Adv Drug Saf 2014; 5: 38-56.

77. Waldbaum S, Liang LP, Patel M. Persistent impairment of mitochondrial and tissue redox status during lithium-pilocarpine-induced epileptogenesis. J Neurochem 2010; 115: 1172-1182.

78. Waldbaum S, Patel M. Mitochondrial dysfunction and oxidative stress: a contributing link to acquired epilepsy? J Bioenerg Biomembr 2010; 42: 449-455.

79. Wang L, Huang H, Cai H, Chen Y. Maternal hypoxia increases hippocampal cell susceptibility to ischemia after middle cere- 
bral artery occlusion in rat offspring. Folia Neuropathol 2017; 55: 317-324.

80. Watanabe Y, Kaida Y, Fukuhara S, Takechi K, Uehara T, Kamei C. Participation of metabotropic glutamate receptors in pentetrazol-induced kindled seizure. Epilepsia 2011; 52: 140-150.

81. Wetmore C, Olson L, Bean AJ. Regulation of brain-derived neurotrophic factor (BDNF) expression and release from hippocampal neurons is mediated by non-NMDA type glutamate receptors. J Neurosci 1994; 14: 1688-1700.

82. Wieser HG. ILAE Commission Report. Mesial temporal lobe epilepsy with hippocampal sclerosis. Epilepsia 2004; 45: 695-714.

83. Willmore LJ. Antiepileptic drugs and neuroprotection: current status and future roles. Epilepsy Behav 2005; 7 Suppl 3: S25-S28.

84. Wirawan E, Vande WL, Kersse K, Cornelis S, Claerhout S, Vanoverberghe I, Roelandt R, De RR, Verspurten J, Declercq W, Agostinis P, Vanden Berghe T, Lippens S, Vandenabeele P. Caspase-mediated cleavage of Beclin-1 inactivates Beclin-1-induced autophagy and enhances apoptosis by promoting the release of proapoptotic factors from mitochondria. Cell DeathDis 2010; 1: e18.

85. Yuen ES, Troconiz IF. Can pentylenetetrazole and maximal electroshock rodent seizure models quantitatively predict antiepileptic efficacy in humans? Seizure 2015; 24: 21-27.

86. Zeng LH, Rensing NR, Wong M. The mammalian target of rapamycin signaling pathway mediates epileptogenesis in a model of temporal lobe epilepsy. J Neurosci 2009; 29: 6964-6972.

87. Zhang S, Wu M, Peng C, Zhao G, Gu R. GFAP expression in injured astrocytes in rats. ExpTherMed 2017; 14: 1905-1908.

88. Zhu JH, Horbinski C, Guo F, Watkins S, Uchiyama Y, Chu CT. Regulation of autophagy by extracellular signal-regulated protein kinases during 1-methyl-4-phenylpyridinium-induced cell death. Am J Pathol 2007; 170: 75-86.

89. Zhu X, Shen K, Bai Y, Zhang A, Xia Z, Chao J, Yao H. NADPH oxidase activation is required for pentylenetetrazole kindling-induced hippocampal autophagy. Free Radic Biol Med 2016; 94 : 230-242. 